\title{
Citizens' behaviours related to smoke in bushfires and their implications for computational models of evacuation
}

\author{
Julie Dugdale \\ University Grenoble Alps, \\ Grenoble Informatics Lab (LIG), \\ France. \\ Julie.Dugdale@imag.fr
}

\author{
Vincent Lemiale \\ Data 61, Commonwealth \\ Scientific and Industrial Research \\ Organisation (CSIRO), Australia. \\ Vincent.Lemiale@data61.csiro. \\ au
}

\begin{abstract}
The behaviours of citizens during bushfires may determine whether they live or die. Using 100 citizen witness statements from the 2009 Australian bushfires, we show how people react to bushfire smoke. Eightynine witnesses expressly mention smoke, not necessarily in combination with fire. This prompted behaviours including: seeking further information, monitoring the situation, effecting a fire plan (including evacuation), alerting people to danger and fire risk, and going home. Computational simulators have been used to assess civilians' risk and to help with evacuation efforts. Despite works that accurately model fire spread and people's behaviours in response to perceiving fire, the issue of how people react to seeing smoke from a bushfire is rarely considered. We discuss how the identified behaviours may be incorporated into an agent-based simulator of bushfire.
\end{abstract}

\section{Introduction}

The recent Australian bushfires in 2019/2020 were the worst on record, with 46 million acres of forest and farmland burned, more than one billion animals killed, thousands of buildings, including homes, destroyed, and at least 34 lives lost [1] [2]. In the early 1990s, the state of Victoria in Australia adopted the bushfire response policy for civilians to 'prepare, stay and defend' or 'prepare and leave early'; known colloquially as the 'Stay or Go' policy [3]. However, since the 2009 bushfires the guidelines have been updated and people are now encouraged to leave before the bushfire threatens [4]. In a recent study, Whittaker reported that since the 2009 bushfires the percentage of householders that planned to leave when threatened by a bushfire had risen from $24 \%$ to $26-$ $65 \%$ [5]. This puts increasing pressure to manage evacuation of the population in a safe and speedy manner.

Evacuation poses a huge problem for emergency managers since they need to ensure that there are a sufficient number of routes out of the danger zone, and that they are safe from fallen trees and embers. In addition, the potentially large number of evacuees means that road congestion can soon become a problem. Therefore, controlled evacuation, with certain zones being evacuated before others, may be practiced. Evacuation relies on the public knowing of the danger and being ready to evacuate. Hence, it is important to carefully schedule warning, alerts, and evacuation messages and to make sure that they are accurate [6] [7].

Large scale evacuation exercises are difficult, costly and often impractical to organise. Therefore, computer simulation of evacuation has become a useful tool. Such simulators often employ a geographical information system (GIS) to model the distribution of households in the environment as well as the transport network. Other components, such as the fuel load of the environment (trees, shrubland, clear areas, etc.) are also included. An important component of the simulator is the fire model. One of the first considerations is the area that the fire model covers, from small scale such as a few buildings, to larger scale models covering hundreds of kilometers. In this work, we are only concerned with the latter. Many fire models can predict the rate of fire spread and its direction. Meteorological information, such as wind speed and direction, and differences in vegetation and terrain, are also often included [8] [9] [10] [11] [12] [13]. Smoke generation from the fire is accounted for and complex smoke models exist that can be incorporated into fire models [14]. Despite these impressive works, the effect of smoke on citizens and in particular how people behave in the face of smoke has received less attention. We argue that smoke, even in the absence of fire, is a trigger for some 
human behaviours and that these should be incorporated into computational models of evacuation.

The paper is organised as follows. Section 2 covers related work on how human behaviours regarding smoke are modelled in evacuation simulators. Section 3 describes our study method, whilst section 4 describes the results of our analysis. The implications of the results for developing bushfire evacuation simulators are discussed in section 5 . Section 6 concludes the paper with a summary of the main findings and a description of future work.

\section{Previous work}

Early works on evacuation modelling mainly used a macro approach employing mathematical equations to simulate the demand load on roads and calculate the average origin-to-destination times [15] [16]. The problem with such macro models is that they track masses as a whole and make unrealistic assumptions regarding individuals' behaviours [17]. To overcome this an agent-based micro simulation approach has become popular. An agent is a computational entity capable of autonomous behaviour. It is able to take information from its environment, make its own decisions and act accordingly. The use of agents in modelling human systems has several advantages over other approaches [18]. Firstly, agent-based systems are able to capture emergent phenomena, such as traffic jams. Secondly, they provide a natural description of a system, which as Bonabeau notes makes the approach much closer to reality. Finally, they are flexible, allowing us to study social systems at different levels of abstraction by varying the complexity of our agents or by aggregating agents into subgroups.

In agent-based evacuation simulators, the agents represent people, groups of people, or more typically vehicles. There are now many evacuation simulators for different types of emergencies and disasters that use an agent-based approach. Some works (for example [19], or [20]) place their efforts on accurately modelling the fire component using an agent-based approach, whilst ignoring the human element. Other works concentrate on emergency response operations to fighting the fire by modelling command and control behaviours of rescue personnel and their decisionmaking process [21]. There have been some works that focus on the behaviour of citizens in the community during a bushfire. Investigating how people's behaviours were affected by cognitive biases during bushfires, Arnaud developed an algorithmic formulation of how biases may be implemented in an agent-based simulator [22]. Mancheva and her colleagues, modelled the behaviours and communications of response personnel and citizens during an Australian bushfire [23]. Although citizens can perceive the fire and take protective actions, such as putting on protective clothing, checking their property for embers, and evacuating to a shelter, there are no actions linked to perceiving smoke. Likewise, Singh and Padgham developed an agent-based model for community evacuations with a realistic approach that uses residents' beliefs, goals, and plans to drive agents' behaviours [24]. In the simulation, residents are ordered to leave the area and drive to designated relief centres. Human behaviour in the model is based on real life, with some agents taking a while before acting on the evacuation order, and some driving to collect loved ones or picking up children from school. Nevertheless, the evacuation is triggered by an Incident Controller who runs the simulation; it does not take into account the mounting road congestion that may occur from people who decide to evacuate beforehand due to seeing the warning signs of smoke. Although many simulators accurately model how agents react to fire, by either sensing it in their perception range, or being informed of the fire danger from official communications, the models do not include any behaviours related to smoke.

\section{Method}

The work used as its basis the 100 lay witness statements $^{1}$ that are included in Volume 4 of the 2009 Victorian Bushfires Royal Commission final report [25]. The statements were freely available on-line as separate files from the Bushfire Cooperative Research Centre until 2016.

The transcripts vary in length from half a page to several pages. The transcripts were searched using the search string 'smo' to find references to smoke, as well as words such as 'smoky' and 'smoldering'. Of the 100 statements, 11 do not mention smoke or any of the associated words (see section 4.1 for a characterisation of those interviewees). We thus excluded these 11 transcripts in looking for behaviours in the face of smoke.

The actions following the sight or smell of smoke, or as a consequence of it being present, were then noted. Actions that were undertaken when fire or embers were also present were not noted since the

\footnotetext{
${ }^{1}$ Ethics approval was granted from the Chair of the Social and Interdisciplinary Human Research Ethics Committee (CSSHREC), CSIRO. Reference 095/20.
} 
action could not be considered as a direct result of just the smoke. Of the 89 transcripts, a total of 672 sentences mentioned the word smoke or its associates. Figure 1 gives the number of mentions of smoke per transcript, which shows that, as would be expected, smoke is a prominent aspect of the threat of, and response to, bushfires.

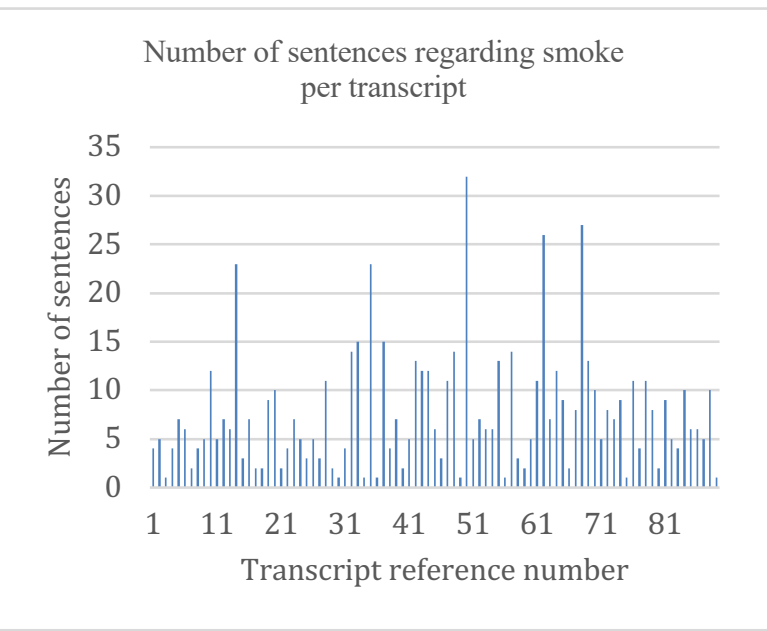

Figure 1. Number of sentences regarding smoke per transcript.

\section{Results}

\subsection{Characterisation of people not mentioning smoke}

Of the 100 statements, 89 people explicitly mention smoke, only 11 people do not mention smoke in their statements (Table 1).

\begin{tabular}{|l|l|l|l|}
\hline $\begin{array}{r}\text { Tranc. } \\
\text { ref. no. }\end{array}$ & $\begin{array}{c}\text { Involved } \\
\text { in fire? } \\
\text { (Yes/No) }\end{array}$ & $\begin{array}{l}\text { Present in } \\
\text { professional } \\
\text { capacity }\end{array}$ & Comments \\
\hline 0 & No & $\begin{array}{l}\text { Lost many family } \\
\text { members. Statement } \\
\text { made to highlight } \\
\text { support and services to } \\
\text { bereaved families for } \\
\text { the Royal Commission. }\end{array}$ \\
\hline 6 & No & $\begin{array}{l}\text { Brother died in the } \\
\text { fire. }\end{array}$ \\
\hline 27 & No & & $\begin{array}{l}\text { Lost partner who died } \\
\text { while defending his } \\
\text { property. }\end{array}$ \\
\hline 33 & No & & $\begin{array}{l}\text { Lost son, wife and 2 } \\
\text { grandchildren who died }\end{array}$ \\
\hline
\end{tabular}

\begin{tabular}{|c|c|c|c|}
\hline & & & $\begin{array}{l}\text { while trying to } \\
\text { evacuate. }\end{array}$ \\
\hline \begin{tabular}{|l|}
75 \\
\end{tabular} & & Yes & $\begin{array}{l}\text { Nurse who worked in } \\
\text { a makeshift medical } \\
\text { facility (tent) to help } \\
\text { victims. }\end{array}$ \\
\hline 10 & & Yes & $\begin{array}{l}\text { CFA volunteer who } \\
\text { helped to fight the fire. } \\
\text { Lost aunt and uncle. } \\
\text { Cousin's property was } \\
\text { totally destroyed. }\end{array}$ \\
\hline 98 & & Yes & $\begin{array}{l}\text { Statement given as an } \\
\text { expert on horticulture } \\
\text { and agriculture } \\
\text { regarding risk } \\
\text { reduction. }\end{array}$ \\
\hline 99 & & Yes & $\begin{array}{l}\text { Statement given as an } \\
\text { expert concerning } \\
\text { community and fire } \\
\text { safety issues. }\end{array}$ \\
\hline 21 & Yes & & $\begin{array}{l}\text { Planned to defend, was } \\
\text { well equipped, and had } \\
\text { a fire plan. However, } \\
\text { he had never } \\
\text { experienced a bushfire } \\
\text { and evacuated as was } \\
\text { overwhelmed by fire. } \\
\text { The transcript does not } \\
\text { detail his experience } \\
\text { during the fire. }\end{array}$ \\
\hline \begin{tabular}{|l}
69 \\
\end{tabular} & Yes & & $\begin{array}{l}\text { House successfully } \\
\text { defended, but the } \\
\text { stables (occupation: } \\
\text { horse breeder) and } \\
\text { other buildings were } \\
\text { destroyed, } 10 \text { horses } \\
\text { died. }\end{array}$ \\
\hline 71 & Yes & & $\begin{array}{l}\text { Lost wife and son } \\
\text { while evacuating. Wife } \\
\text { and son returned home } \\
\text { in a separate car and } \\
\text { perished. }\end{array}$ \\
\hline
\end{tabular}

In summary, of the 11 people who did not mention 'smoke' in their statements, 4 were not directly involved in the fire, but had lost close family members; 4 were involved from a professional point of view (fire-fighter, nurse, vegetation specialist, community resilience worker). Only 3 of the 11 , shown by the grey cells in table 1, were directly involved in the fire. The above table shows that smoke is strong environmental cue and, as we will see in the next section, it evokes specific behaviours.

\subsection{Most common behaviours associated with smoke}

4.2.1. Seek information. Many people reported that they were actively listening to the radio or 
regularly checking bushfire information websites throughout the danger period. However, the sight or smell of smoke often provoked an action to seek information, whether this was turning on the radio or calling friends, neighbours or relatives. 24 of the 89 transcripts $(27 \%)$ mentioned that smoke prompted them to search for information. In terms of the most popular sources of information, many turned to the County Fire Authority, CFA, websites (13 references to this source) or the radio ( 8 references to this source) when they saw smoke. Others either phoned their neighbours, friends, family, the local police station, the bushfire hotline, or consulted the Bureau of Meteorology website.

Although many people turned to the radio or official websites for information, there are many criticisms concerning the lack of, or timeliness of information. This meant that some citizens relied on smoke to give them more accurate information:

"During the day I was listening to the radio but from what I could see of the smoke around the valley the updates on the radio were always behind." (Ref transcript 23)

What may seem strange to us now is the lack of reference in the transcripts to any social media as a source of information. Social media, and in particular Twitter, has been used for many years for citizens to develop awareness of the unfolding situation [26] [27], coordinate support efforts [28], and provide and receive information from emergency management authorities [29], both during and after the disaster [30]. There is evidence that social media was used as a source of information on bushfires by newspapers [31] and radio stations. This includes ABC Radio Melbourne, the main radio station in the state where the fires were burning [32]. However, the low uptake of Twitter in the years leading up to and including 2009 could explain its limited use. In their study Sinnappan and her colleagues found only 1684 tweets from 705 unique users as the bushfire events unfolded between the $6^{\text {th }}$ and the $14^{\text {th }}$ February, 2009 [32].

4.2.2. Monitor the situation. Smoke not only alerted people to danger, but was used to monitor the ongoing situation. From the 89 transcripts, 56 (63\%) describe an activity that can be interpreted as using smoke to monitor the situation. Examples from the transcripts that show this are as follows:

"I went in and out of the house all day checking for any signs of fire, particularly smoke." (Ref transcript 2).

"By watching the smoke, which was clearly visible from my home, I kept close tabs on where the fire was burning and it was growing each day." (Ref transcript 11).
"We continued to monitor the smoke." (Ref transcript 40).

"On such days our routine is to observe the countryside from various viewpoints, look up to the mountains, monitor where the wind is blowing from and just watch out for smoke." (Ref transcript 74).

It was clear from the transcripts that citizens as well as the CFA were frequently using the sighting of smoke to indicate the location of the fire. As a CFA officer notes:

"We were reliant on visual observations of the smoke plume for our information of the passage of the fire and on telephone calls to the observers at the Kangaroo Ground Tower, who said they had limited visibility due to the smoke." (Ref transcript 40).

What is also interesting is that people frequently commented on the form or colour of the smoke and it was clear that this was used as an indicator of the location of the fire, or how the fire was progressing. Out of the 89 transcripts $49(55 \%)$ mentioned the colour, density or form of the smoke.

"I went back outside to check it again and I saw that the smoke had become thicker. Again, the smoke was still not within breathing distance, but it was no more than one kilometre away." (Ref transcript 2).

"I observed that the smoke column was continually growing and getting darker in colour - a sure sign that the fire was hot." (Ref transcript 40).

"At that point we looked up and saw a big black cloud of smoke coming, which was different to what we had seen coming over from Kilmore." (Ref transcript 23).

A small minority of people, 4 out of the 89 , said that upon seeing the smoke they moved to a position by car to get a better look. Sometimes this was to monitor the situation more closely, and sometimes this was just out of curiosity.

4.2.3. Effect fire plan (Evacuate or Prepare and Defend). In 2009 Australian state and territory fire authorities advised citizens either to 'stay and defend' or 'leave early'. To practically implement this policy, the CFA of Victoria advised citizens to prepare a fire plan in advance of the fire season and that the plan should be written down and well-practised. For the 2009 bushfires, half the population that responded to a survey said that they intended to stay and defend, while only $21 \%$ intended to leave, $26 \%$ people tended to adopt a wait and see approach [5].

Perhaps one of the most obvious behaviours prompted by seeing or smelling smoke in the transcripts was to instigate a fire plan. Seeing both smoke and fire is a clear indicator that there is danger. However, if we consider those respondents who reacted to smoke alone, 23 of the 89 respondents 
(26\%) were prompted to implement their fire plan. However, several points should be taken into account. The first is that people had often been monitoring the fire-risk situation for several hours, in some cases days, via news outlets and websites. This meant that they were already alert to the danger and the possible risks. The second is how long it took people to start implementing their plan upon the first sighting of smoke. Some respondents clearly reacted immediately:

"As soon as we saw smoke, we prepared the fire pump and got out our other smaller pieces of equipment such as mops, buckets and our fire box." (Ref transcript 48).

Whilst others monitored the smoke and waited until it came closer or changed in density or colour. In the following excerpt smoke was noticed at $3.30 \mathrm{pm}$, but the respondents waited one and a half hour before starting the garden sprinklers, and only got the large fire hose out two and a half hours after the first sighting and when the smoke became dense and fastmoving:

"At around $3.30 \mathrm{pm}$, I noticed smoke from a big fire far to the South-West, approximately $30-40 \mathrm{~km}$ away...The smoke was a huge mushroom cloud, it looked like a nuclear bomb had just gone off but it was a long way away. By $5.00 \mathrm{pm}$ however, it seemed closer so we decided to start soaking the sides of the house using the garden sprinklers...By $6.00 \mathrm{pm}$ there were heavy fast-moving rolling palls of smoke in the sky so I laid out the big fire hose." (Ref transcript 77).

Some of the respondents had a plan to evacuate immediately, while others waited to see what would happen. 10 respondents evacuated in response to seeing smoke, with no sightings of fire. Some evacuated immediately, for example:

"I could not hear anything but I could smell the smoke. It was about 6:20pm when we drove out of our driveway with our two dogs and headed into Traralgon." (Ref transcript 17).

Others were obviously caught out and had waited too long before evacuation. Although, there was still no sightings of fire, the smoke in itself had become dangerous and promoted evacuation, for example:

"I couldn't see any flames at that stage but the smoke and embers were so thick that it was obvious that the fire had hit the surrounding bush." (Ref transcript 79).

As we see from the above example, the decision to evacuate was not just prompted by smoke but also by seeing embers and often the sound of the fire. For those that evacuated late, what is clear from the descriptions in the transcripts is that visibility during evacuation was greatly affected. Many respondents reported that the sky was black and that they had problems seeing. This undoubtedly affected the speed of evacuation.

"He said both sides of the road were burning and the smoke was so thick that he couldn't see past the bonnet of his car and burning branches were hitting his car and that he was full of fear." (Ref transcript 12).

"The smoke was like really thick fog. It was difficult to read the road signs and people were panicking, with cars heading in different directions" (Ref transcript 4).

4.2.4. Alerting people to danger and to the fire risk. On seeing or smelling smoke the majority of people were alerted to danger, as the following examples show:

"Even though the smoke was coming from Kilmore, we realized it was a threat to our property." (Ref transcript 61).

"Late in the afternoon, I went out into our backyard and I noticed some grey-white smoke off in the distance [.....]. My immediate thought was that Marion would need to stay inside and I cautioned her to do so." (Ref transcript 2).

This warning to the fire risk did not necessarily come from seeing smoke alone but was often in association with other factors, such as earlier news broadcasts or the prolonged extremely hot weather.

Nevertheless, 14 people $(16 \%)$ did not consider that smoke indicated a danger or was an immediate precursor to fire. This was either due to previous experience where smoke had been seen in the past but there was no immediate danger of fire, or because people thought that it was a controlled burning exercise. The following comments show these points:

"I wasn't panicking at all at this stage because I had smelt smoke during a previous fire that burned near Malmsbury and that fire never got anywhere near us." (Ref transcript 96).

"Even when I saw that smoke I was concerned but not alarmed - we had seen smoke in the sky in previous years from various distant fires." (Ref transcript 87).

"Although there was some smoke in the air, I thought it was a burn off." (Ref transcript 49).

4.2.5. Go home. Since the $7^{\text {th }}$ February was a Saturday, the majority of respondents were at home when the bushfires occurred. Some people however were at work, shopping, or out visiting friends, etc. Upon seeing the smoke 9 of the 89 respondents (10\%) decided to go home as the examples below show:

"I told her I was going to go home because I was a bit worried about the smoke that I could see in the distance." (Ref transcript 52) 
"I immediately went home and at about $3.45 \mathrm{pm}$, I took a photo from my veranda of the horizon obscured by smoke." (Ref transcript 82)

It should be noted that the majority of these people had a fire plan that involved defending their home.

\section{Implications for modelling and simulation}

Although the above activities can be taken into account in models of human behaviours in bushfire events, it is first important to consider to what level human behaviours should be modelled. That is, whether human activities should be modelled at a finely grained level, such as individual communications when searching for information, or at a coarser grain, such as general evacuation. Low level behaviours, such as searching for information, calling friends and family, etc. can have a significant impact on evacuation time if we consider the cumulative time taken for these activities [33]. A clear assumption in human behaviour models of bushfire evacuation is that upon receiving an evacuation order, people will immediately start to evacuate. From the transcripts, this is clearly not the case. People perform a plethora of activities (collecting belongings and pets, telephoning others, packing the car, etc.) before they evacuate. The time taken for these pre-evacuation behaviours is rarely taken into account in fire evacuation simulators. Although it can be hard to gauge how long people spend on average performing these activities, some work has been done in the area. Based on field studies and a literature search, Bangate identified, modelled and simulated 37 individual preevacuation human behaviours, each with timing intervals, in the case of earthquakes [33]. The duration of these activities was used to estimate the delay before actual evacuation occurred.

Evacuation models also assume perfect visibility during evacuation. From the preponderance of transcripts that describe the difficulty of people to see others, objects, signs, etc. due to the smoke, it is evident that evacuation speed is greatly reduced when high density smoke is present. A consequence of this for simulation is to reduce the travel speed depending on the density of the smoke as predicted by smoke models. Although there have been studies that look at how individuals walking speeds are affected by smoke during evacuation, e.g. [34], there are few works that look at how people drive in smoke-filled areas. Driving in smoke has been liked to driving in fog and indeed the two are often treated equally in transport studies [35]. In order to incorporate the effect of smoke on driving, it is necessary to assess how speed varies according to smoke and then to calibrate the vehicle speed in the simulator. In a simulated experiment Yan and his colleagues looked at how driver speed was affected by different densities of fog (no fog, light, and heavy) and gave speeds for each density for various types of road [36]. A study that looks specifically at car driving behaviour in smoke during evacuation in a bushfire was undertaken by Wetterberg. By employing virtual reality, he asked participants to drive in an ad hoc wildfire evacuation scenario. From his results a regression model, which related the speed with the smoke density, was developed [37]. Given that both of the above studies use virtual reality, it cannot be assumed that the drivers experience the same risk perception and levels of stress as they would have in real life. Nevertheless, these works do give us a starting point in calibrating car speed in the face of smoke.

Although increasing numbers of people intend to evacuate, many will stay to defend their homes and livelihoods, or return to elderly or dependent relatives. After the 2009 bushfires, the fire danger ratings that are available to the public to show the fire risk in their area were revised. Two new categories were introduced by the New South Wales government: severe and catastrophic [38]. The highest category, catastrophic, advises that for survival, leaving is the only option. Despite this, a recent study found that even now 10 to $34 \%$ still plan to stay and defend [5]. If these people are away from their homes then they will return and start their defense fire plan. In terms of modelling and simulation, we cannot assume that all citizens will necessarily evacuate and that, taking a conservative figure, $10 \%$ will try to return to their homes. Some will be stopped by road blocks but others will attempt to bypass them and use unofficial backroads to get home [39].

There is clear evidence that people use smoke as: an alert to danger, to seek further information, to monitor the situation, to trigger a fire plan, or to go home. However, there are some people $(16 \%$ in the transcripts) who will not react to sightings of smoke. With the predicted increase in extreme bushfires due to climate change estimated to rise by $30 \%$ by 2017 [40] fires will become more common and people may become increasingly complacent in their response to seeing smoke. This may be exacerbated by the increase in prescribed controlled burning, which has risen since 2004 [41]. Although we may think that an increase in the number of bushfires may increase people's awareness of bushfire risk and so result in them being more responsive to sightings of smoke, this is not necessarily the case. Indeed, even after the bushfires of 2009, people still have a limited awareness of bushfire risk [5] and there is no clear 
relationship between increased risk perception and taking action [42]. This would imply that a percentage of the population will continue not to react to smoke. In terms of modelling and simulation this means that a percentage of the people modelled cannot be assumed to take actions when faced with smoke. From the transcripts, this was $16 \%$.

\section{Conclusion}

The number and severity of bushfires is estimated to increase in the coming years due to climate change. Effective evacuation therefore becomes a critical issue, which has been aided by computer simulations that can assess different strategies and policies. It is now recognised that human behaviours must be taken into account in such situations. However, how people react to bushfire smoke is rarely included in such simulations. Using empirical evidence, we have shown how smoke is an important factor that can trigger peoples behaviours. Six main behaviours were identified: seeking further information, monitoring the situation, effecting a fire plan (including evacuation), alerting people to danger and fire risk, and going home. We argue that in order to be more realistic, future computer simulation should take into account not only the perception of the fire, warnings, and evacuation order, but how people react to seeing or smelling smoke.

The work has several limitations. Firstly, as qualitative research, the analysis of the transcripts was subjective. Although the authors have been working for many years in the areas of bushfires and qualitative research, the analysis may still be influenced by their personal perspectives. Secondly, the analysis concerns the fires that occurred on the $7^{\text {th }}$ February 2009 in the state of Victoria. Although this was Australia's worst bushfire disaster in terms of lives lost, these fires are not the most recent, nor the most wide-spread. Unfortunately, an analysis of the most recent fires in $2019 / 2020$ is still being conducted by the authorities and so no official reports are available. This meant that we had to base our work on the 2009 bushfires. Finally, the analysis only included what was actually written in the statements. Some people may have done certain actions, such as using smoke as a trigger for monitoring how the fire was evolving, but did not explicitly mention it in their statements.

\section{References}

[1] Lockie, S. (2020) Sociological responses to the bushfire and climate crises, Environmental
Sociology, $6: 1, \quad 1-5, \quad$ DOI: $10.1080 / 23251042.2020 .1726640$

[2] University of Sydney. (2020) "More than one billion animals impacted in Australian bushfires". 8 January 2020. https://www.sydney.edu.au/newsopinion/news/2020/01/08/australian-bushfiresmore-than-one-billion-animals-impacted.html. Retrieved 13 March 2020.

[3] Reynolds, B. (2017). A history of the Prepare, Stay and Defend or Leave Early policy in Victoria. PhD thesis, RMIT, Melbourne, Australia. February 2017.

[4] AFAC (Australasian Fire and Emergency Services Authorities Council). 2019. Bushfires and community Safety. Version $6.09^{\text {th }}$ April 2019. https://afac.com.au/insight/doctrine/article/curren t/bushfires-and-community-safety. Accessed $17^{\text {th }}$ March 2020.

[5] Whittaker, J. (2019). Ten years after the black Saturday fires, what have we learnt from post-fire research? Australian Journal of Emergency Management, The, 34(2), 32.

[6] Whittaker, J., Taylor, M., \& Bearman, C. (2020). Why don't bushfire warnings work as intended? Responses to official warnings during bushfires in New South Wales, Australia. International Journal of Disaster Risk Reduction, 101476.

[7] Sorensen, J. H. (2000). Hazard warning systems: Review of 20 years of progress. Natural hazards review, 1(2), 119-125.

[8] Miller, C., Hilton, J., Sullivan, A., \& Prakash, M. (2015, March). SPARK-A bushfire spread prediction tool. In International Symposium on Environmental Software Systems (pp. 262-271). Springer, Cham.

[9] Paterson, G., \& Chong, D. (2011). Implementing the Phoenix fire spread model for operational use. In Surveying and Spatial Sciences Conference ( $\mathrm{p}$. 111).

[10] Tolhurst, K., Shields, B., \& Chong, D. (2008). Phoenix: development and application of a bushfire risk management tool. Australian Journal of Emergency Management, 23(4), 47-54.

[11] Johnston, P., Milne, G., \& Klemitz, D. (2005). Overview of bushfire spread simulation systems. BUSHFIRE CRC Project B, 6 .

[12] Kelso, J. K., Mellor, D., Murphy, M. E., \& Milne, G. J. (2015). Techniques for evaluating wildfire simulators via the simulation of historical fires using the Australis simulator. International Journal of Wildland Fire, 24(6), 784-797.

[13] Hoffman, C. M., Canfield, J., Linn, R. R., Mell, W., Sieg, C. H., Pimont, F., \& Ziegler, J. (2016). Evaluating crown fire rate of spread predictions 
from physics-based models. Fire Technology, 52(1), 221-237.

[14] Goodrick, S. L., Achtemeier, G. L., Larkin, N. K., Liu, Y., \& Strand, T. M. (2013). Modelling smoke transport from wildland fires: a review. International Journal of Wildland Fire, 22(1), 8394.

[15] Sheffi, Y., Mahmassani, H., \& Powell, W. B. (1982). A transportation network evacuation model. Transportation research part A: general, 16(3), 209-218.

[16] Southworth, F., \& Chin, S. M. (1987). Network evacuation modelling for flooding as a result of dam failure. Environment and Planning A, 19(11), 1543-1558.

[17] Pel, A. J., Bliemer, M. C., \& Hoogendoorn, S. P. (2012). A review on travel behaviour modelling in dynamic traffic simulation models for evacuations. Transportation, 39(1), 97-123.

[18] Bonabeau, E. (2002) 'Agent-based modeling: methods and techniques for simulating human systems'. In Proc. National Academy of Sciences 99(3): 7280-7287.

[19] Niazi, M. A., Siddique, Q., Hussain, A., \& Kolberg, M. (2010, April). Verification \& validation of an agent-based forest fire simulation model. In Proceedings of the 2010 Spring Simulation Multiconference (pp. 1-8).

[20] Li, X., \& Magill, W. (2001). Modeling fire spread under environmental influence using a cellular automaton approach. Complexity International, $8(1), 1-14$.

[21] Bruggemann, T., Ford, J., White, G., \& Perez, T. (2019). Bushfire emergency response simulation. In Proceedings of the 23rd International Congress on Modelling and Simulation (MODSIM2019) (pp. 49-55). The Modelling and Simulation Society of Australia and New Zealand Inc.

[22] Arnaud, M., Adam, C., \& Dugdale, J. (2017, May). The role of cognitive biases in reactions to bushfires. International Conference on Information Systems for Crisis Reposnse and Management (ISCRAM). Albi, France. 21st-24th May, 2017.

[23] Mancheva, L., Adam, C., \& Dugdale, J. (2019, May). Multi-agent geospatial simulation of human interactions and behaviour in bushfires. International Conference on Information Systems for Crisis Response and Management (ISCRAM). Valencia, Spain. May, 2019.

[24] Singh, D., \& Padgham, L. (2015, May). Community evacuation planning for bushfires using agent-based simulation. In Proceedings of the 2015 International Conference on
Autonomous Agents and Multiagent Systems (pp. 1903-1904).

[25] Victorian Bushfires Royal Commission, and Teague, B. (2010). 2009 Victorian Bushfires Royal Commission: Summary. Final Report. The Commission. Volume 4 (DVD-ROM): The statements of lay witnesses (ISBN: 9780980740851).

[26] Sutton, J. N., Palen, L., \& Shklovski, I. (2008). Backchannels on the front lines: Emergency uses of social media in the 2007 Southern California Wildfires. Proceedings of the 5th International ISCRAM Conference. Washington DC, USA. May 2008. Eds: Friedrick, F. and B. Van de Walle.

[27] Power, R., Robinson, B., Wise, C. Using Crowd Sourced Content to Help Manage Emergency Events. In: Nepal, Surya and Paris, Cecile and Georgakopoulos, Dimitrios, editor/s. Social Media for Government Services. Springer; 2015. 247-270. https://doi.org/10.1007/978-3-31927237-5 12

[28] Kaufhold, M. A., \& Reuter, C. (2016). The selforganization of digital volunteers across social media: The case of the 2013 European floods in Germany. Journal of Homeland Security and Emergency Management, 13(1), 137-166.

[29] Reuter, C., Ludwig, T., Kaufhold, M. A., \& Spielhofer, T. (2016). Emergency services' attitudes towards social media: A quantitative and qualitative survey across Europe. International Journal of Human-Computer Studies, 95, 96-111.

[30] Houston, J. B., Hawthorne, J., Perreault, M. F., Park, E. H., Goldstein Hode, M., Halliwell, M. R., ... \& Griffith, S. A. (2015). Social media and disasters: a functional framework for social media use in disaster planning, response, and research. Disasters, 39(1), 1-22.

[31] Dowdell-Baker, J. "Understanding how social media is used as a news source during crisis events." PhD diss., University of Tasmania, 2013.

[32], Suku Sinnappan, Cathy Farrell, and Elizabeth Stewart. "Priceless tweets! A study on Twitter messages posted during crisis: Black Saturday." ACIS 2010 Proceedings 39 (2010).

[33] Bangate, J. Multi-agent modelling of seismic crisis. (2019) $\mathrm{PhD}$ thesis. University Grenoble Alps, France.

[34] Ronchi, E., Gwynne, S.M.V., Purser, D.A. et al. Representation of the Impact of Smoke on Agent Walking Speeds in Evacuation Models. Fire Technol 49, 411-431 (2013). https://doi.org/10.1007/s10694-012-0280-y

[35] Abdel-Aty, M., Ekram, A. A., Huang, H., \& Choi, K. (2011). A study on crashes related to visibility 
obstruction due to fog and smoke. Accident Analysis \& Prevention, 43(5), 1730-1737.

[36] Yan, X., Li, X., Liu, Y., \& Zhao, J. (2014). Effects of foggy conditions on drivers' speed control behaviors at different risk levels. Safety Science, $68,275-287$.

[37] Wetterberg, N. (2020). A virtual reality experiment on driving speed in smoke during a wildfire evacuation. $L U T V D G / T V B B$.

[38] New South Wales Rural Fire Service (2018) Fire Danger Ratings. Available from: https://www.rfs.nsw.gov.au/fire-information/fdrand-tobans? $\mathrm{a}=1421$. Accessed $17^{\text {th }}$ March 2020.

[39] Wilkinson, C., Eriksen, C., \& Penman, T. (2016). Into the firing line: civilian ingress during the 2013 "Red October" bushfires, Australia. Natural Hazards, 80(1), 521-538.

[40] Sharples, J. J., Cary, G. J., Fox-Hughes, P., Mooney, S., Evans, J. P., Fletcher, M. S., ... \& Baker, P. (2016). Natural hazards in Australia: extreme bushfire. Climatic Change, 139(1), 8599.

[41] Government of South Australia (2011). Prescribed burning in South Australia: Review of operational prescriptions. Department of Environment and Natural Resources. www.environment.sa.gov.au. Accessed $19^{\text {th }}$ March 2020.

[42] Muir, C., Gilbert, J., O’Hara, R., Day, L., \& Newstead, S. (2017). Physical bushfire preparation over time in Victoria, Australia. Disaster Prevention and Management: An International Journal. 